\title{
PELATIHAN PEMBUATAN PUPUK ORGANIK CAIR PADA KELOMPOK TANI DI KABUPATEN PROBOLINGGO
}

\author{
TRAINING FOR MAKING LIQUID ORGANIC FERTILIZER IN LAND GROUPS \\ IN PROBOLINGGO DISTRICT
}

\author{
Tini Surtiningsih \\ Fakultas Sains dan Teknologi \\ Fatimah \\ Fakultas Sains dan Teknologi \\ Ni'matuzahroh \\ Fakultas Sains dan Teknologi \\ Agus Supriyanto \\ Fakultas Sains dan Teknologi \\ Tri Nurhariyati \\ Fakultas Sains dan Teknologi
}

\begin{abstract}
ABSTRAK
Pengabdian kepada masyarakat ini bertujuan untuk menerapkan cara pembuatan dan pupuk organik cair dan meningkatkan keterampilan petani dalam membuat pupuk organik cair. Selain itu untuk mengurangi ketergantungan kelompok tani terhadap pupuk anorganik dan memanfaatkan hasil limbah tebu yaitu molase dan mikroba sebagai formula dalam pembuatan pupuk organik cair. Metode yang dilakukan adalah peningkatan wawasan mengenai pupuk organik cair, dan cara pembuatannya. Hasil sosialisasi pupuk organik cair menunjukkan bahwa wawasan kelompok tani meningkat rata-rata sebesar $77 \%$ melalui nilai pretest dan post test saat sosialisasi. Berdasarkan evaluasi menunjukkan bahwa kelompok tani telah mampu membuat pupuk organik cair secara mandiri. Sosialisasi pembuatan pupuk organik cair memberikan tambahan wawasan bagi kelompok tani terhadap pemanfaatan pupuk organik cair bagi pertanian.
\end{abstract}

Kata kunci: pupuk organik cair, kelompok tani, pelatihan

\section{ABSTRACT}

This community service aims to apply the method of making and liquid organic fertilizer and improving the skills of farmers in making liquid organic fertilizer. In addition to reducing the dependence of farmer groups on inorganic fertilizers and utilizing the results of sugarcane waste, namely molasses and microbes as a formula in the manufacture of liquid organic fertilizer. The method that was carried out was to increase insight into liquid organic fertilizer, and how to make it. The results of the socialization of liquid organic fertilizers showed that the insights of farmer groups increased by an average of $77 \%$ through the pretest and post test values during socialization. Based on the evaluation shows that the farmer group has been able to make liquid organic fertilizer independently. The socialization of making liquid organic fertilizer provides additional insight for farmer groups on the use of liquid organic fertilizer for agriculture.

Keywords: liquid organic fertilizer, farmer group, training 


\section{PENDAHULUAN}

\section{Latar Belakang}

Pencemaran dan kerusakan lahan pertanian makin meningkat sejalan dengan penggunaan dosis tinggi pupuk kimia oleh para petani. Akibat lain dari pemberian pupuk kimia menimbulkan fenomena dampak negatif terhadap ekosistem pertanian, contohnya; pengerasan tanah, kehilangan materi organik, kontaminasi logam berat dari senyawa-senyawa kimia dan rusaknya struktur tanah karena sebagian besar pupuk kimia akan di jerap oleh tanah, sehingga lahan pertanian menjadi keras dan sukar diolah, perkembangan akar tanaman menjadi tidak sempurna akibatnya produksi pertanian semakin menurun.

Penggunaan kelompok mikroba sebagai pupuk organik cair yang diperlukan oleh tanaman dapat dipakai sebagai pengganti pupuk kimia. Kelompok mikroba yang masuk sebagai pupuk organik cair diantaranya adalah bakteri dari genus Bacillus dan Pseudomonas yang berperan sebagai bakteri pelarut fosfat (Alexander, 1978; Buntan, 1992; Illmer et al., 1995) dan Azospirillum, Azotobakter sebagai organisme pemfiksasi nitrogen dan bakteri Rhizobium yang bersimbiosis dengan akar tanaman Leguminoceae merupakan bakteri pemfiksasi N (Goenandi, 2004), golongan yeast Saccharomyces cereviceae.

Secara umum kelompok petani masih tergantung kepada pupuk anorganik/kimia yang harganya relatif mahal. Dengan demikian perlu diberikan pelatihan kepada kelompok petani tentang pemahaman pupuk organik cair dan teknik pembuatannya dan aplikasi riil di lapangan yang belum dikuasai. Diharapkan setelah pelatihan ini, kelompok Tani dapat membuat pupuk organik cair secara mandiri, sehingga biaya pemupukan secara umum dapat diminimalkan.

\section{Rumusan Masalah}

Hasil diskusi mitra pengabdian, maka permasalahan yang di hadapi saat ini adalah:

a. Kelompok petani masih tergantung kepada produsen pupuk organik cair yang harganya relatif mahal.

b. Pengetahuan dan teknik dalam pembuatan pupuk organik masih kurang.

\section{Tinjauan Pustaka}

Pupuk Organik Cair adalah formulasi dari mikroorganisme hidup yang mampu mengubah unsur hara dari bentuk yang belum dapat digunakan menjadi bentuk tersedia bagi tanaman melalui proses biologi baik dengan hidup bebas di dalam tanah atau berasosiasi dengan tanaman (Subba Rao et al., 1993). Saat ini, Pupuk Organik Cair dipergunakan untuk memengaruhi peningkatan hasil panen berkelanjutan di bawah berbagai kondisi iklim agronomi. Pupuk Organik Cair sebagai bahan pembawa mikroba hidup berperan sebagai sumber daya yang murah untuk meningkatkan ketersediaan nutrisi tanaman juga dapat mensintesis faktor pertumbuhan tanaman (Subba Rao et al., 1982).

Menurut Musnamar (2003) dan Suriawiria (2002) beberapa manfaat pupuk organik antara lain: a) meningkatkan kesuburan tanah; b) memperbaiki kondisi kimia, fisika, dan biologi; c) meningkatkan daya serap dan daya pegang tanah terhadap air; d) memperbaiki kehidupan organisme tanah; e) aman bagi kehidupan manusia dan lingkungan; f) meningkatkan produksi pertanian; g) mengendalikan penyakit-penyakit tertentu.

Pupuk organik mempunyai peluang cukup besar karena berbagai kendala yang dimiliki pupuk organik dapat diatasi, misalnya dengan pengayaan unsur hara dan penambahan berbagai mikroba. Selain itu bahan baku tersedia sepanjang waktu, harganya murah, dan memudahkan proses pengomposan bahan organik.

Dengan meningkatnya kesadaran petani akan bahaya residu pemakaian pupuk anorganik membuat peluang pemakaian pupuk organik semakin besar.

\section{Tujuan dan Manfaat}

Tujuan dari program pengabdian

a. Memberikan pengetahuan dan pemahaman kepada petani tentang pupuk organik cair

b. Memberikan bekal keterampilan kepada petani tentang teknik pembuatan pupuk organik cair

c. Memberikan bekal kepada petani tentang cara penggunaan pupuk organik cair pada tanaman pertanian

Manfaat bagi para petani, selain mendapatkan ilmu yang berharga mengenai teknik pembuatan pupuk organik juga meningkatkan taraf ekonomi, menciptakan lapangan kerja baru, mengurangi pencemaran lingkungan, dan memperbaiki sifat fisik, kimia, dan biologi tanah.

\section{METODE PENGABDIAN}

Metode pengabdian kepada masyarakat dilakukan dengan beberapa tahapan yang dijelaskan pada sub bab 1 hingga 3 .

\section{Waktu dan Tempat Pengabdian}

Waktu pelaksanaan Program Pengabdian Masyarakat adalah pada tanggal 6 Agustus 2017. Tempat pelaksanaan di Desa Duren, Kecamatan Gading, Kabupaten Probolinggo Jawa Timur.

\section{Metode dan Rancangan Pengabdian}

Pelaksanaan kegiatan IbM ini dilakukan dengan beberapa langkah, yaitu: perencanaan, tindakan, observasi dan evaluasi. Kegiatan-kegiatan atau aktivitas-aktivitas dari masing-masing tahapan adalah sebagai berikut. 


\section{Perencanaan}

Kegiatan-kegiatan yang dilakukan pada tahap perencanaan adalah:

1. Sosialisasi program Pengabdian kepada Masyarakat kepada kelompok tani di desa Duren kecamatan Gading kabupaten Probolinggo untuk pemaparan program pelatihan.

2. Penyusunan modul pembuatan pupuk organik cair untuk petani di desa Duren kecamatan Gading kabupaten Probolinggo.

\section{Tindakan}

Tindakan dalam kegiatan ini berupa implementasi program pelatihan. Kegiatan-kegiatan yang dilakukan dalam implementasi program adalah:

1. Peningkatan pengetahuan pembuatan pupuk organik cair kepada kelompok tani. Metode yang ditawarkan adalah ceramah, tanya jawab, diskusi.

2. Pelaksanaan pelatihan dilakukan baik secara teori maupun praktek dengan narasumber ahli, yaitu dari tim pengabdian kepada masyarakat. Materi yang diberikan adalah pelatihan teori dan praktek pembuatan pupuk organik cair. Metode pelatihan yang digunakan adalah ceramah, tanya jawab, diskusi dan latihan.

3. Pembinaan dan pelatihan dimulai dari persiapan dan pembuatan, cara perbanyak pupuk organik, dan cara pemanenan. Pembinaan manajemen bisnis dan pemasaran juga dilakukan bersamaan dengan pelatihan budidaya. Metode pelatihan yang digunakan adalah ceramah, tanya jawab, diskusi dan latihan. Untuk mendukung keberhasilan pelatihan dan produksi diberikan bantuan 2 jerigen pupuk organik cair.

\section{Observasi dan Evaluasi}

Observasi dilakukan selama masa kegiatan. Beberapa hal yang diobservasi adalah kendala-kendala, kekurangankekurangan, dan kelemahan-kelemahan yang muncul dalam proses pembuatan pupuk organik cair. Evaluasi dilakukan terhadap proses pembuatan, berupa kuantitas dan kualitas pemahaman terhadap pembuatan pupuk organik cair dari hasil pretest dan post test. Evaluasi ini dilakukan dalam rangka untuk menetapkan rekomendasi terhadap keberlangsungan atau pengembangan kegiatan-kegiatan berikutnya.

\section{Peserta Pelatihan}

Peserta pelatihan pembuatan pupuk organik cair ini merupakan kelompok tani Desa Duren, Kecamatan Gading, Kabupaten Probolinggo, sejumlah 30 orang. Selain itu kegiatan ini dihadiri oleh 10 orang Mahasiswa S-1 yang sedang melaksanakan KKN BBM, serta mahasiswa S2 sejumlah 3 orang. Di samping itu, hadir pula 10 orang dosen Biologi FST Unair.

\section{HASIL DAN PEMBAHASAN}

Pengabdian ini dilakukan dengan terlebih dahulu memberikan ceramah dengan kelompok tani. Tujuan dari dilaksanakannya ceramah ini adalah untuk memberikan pengetahuan tentang pengetahuan, pemahaman, dan pembuatan pupuk organik cair. Tindak lanjut dari ceramah adalah diskusi untuk meningkatkan pengetahuan petani mengenai masalah pupuk organik cair, dan pelatihan peningkatan keterampilan pembuatan pupuk organik cair.

Pemberian materi dilakukan baik secara klasikal dalam bentuk ceramah yang dilakukan di rumah pak lurah (Gambar 1). Kegiatan ini bertujuan untuk memberikan pengetahuan mengenai pupuk organik cair sekaligus pembuatannya.

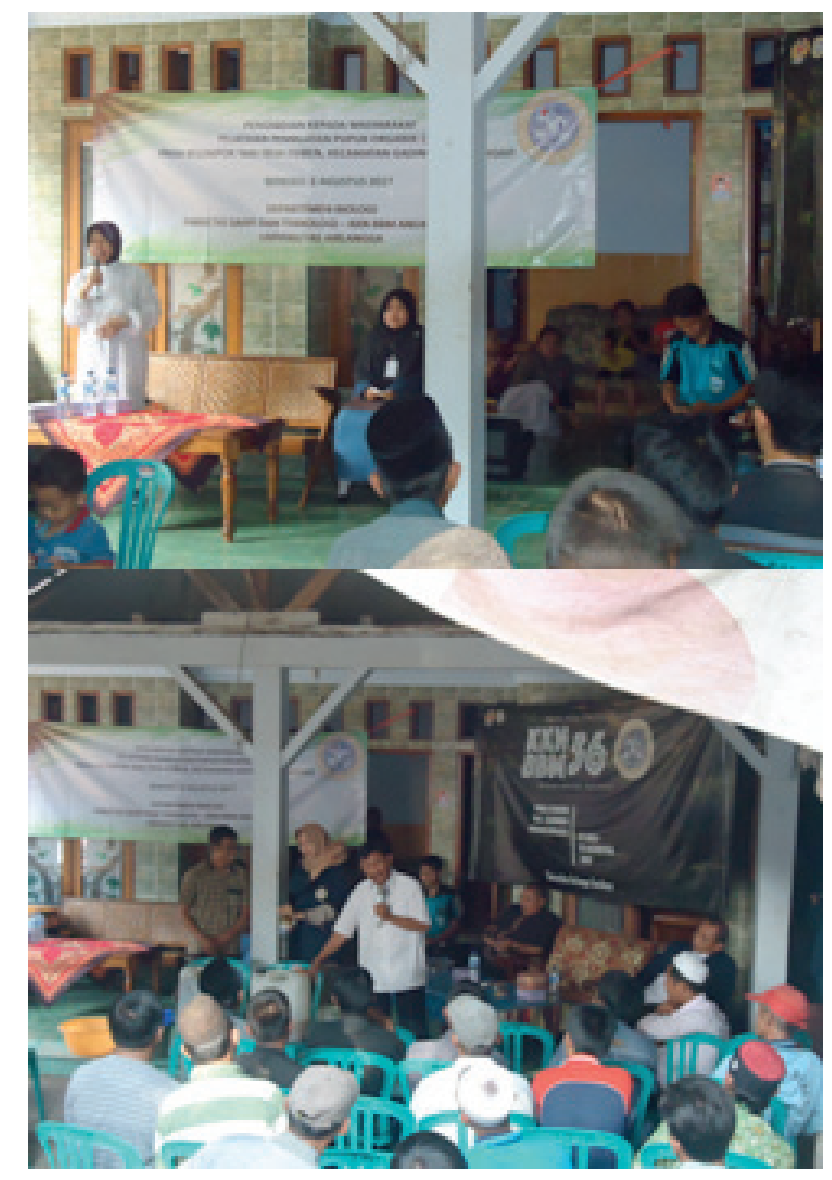

Gambar 1. Ceramah yang dilakukan di rumah pak lurah oleh dosen kepada kelompok petani.

Hasil pemberian materi dievaluasi dalam bentuk pretest dan post test (Gambar 2). Evaluasi pretest dan post test menunjukkan bahwa terdapat peningkatan wawasan dan pengetahuan kelompok tani terkait pupuk organik cair dan pembuatannya. 


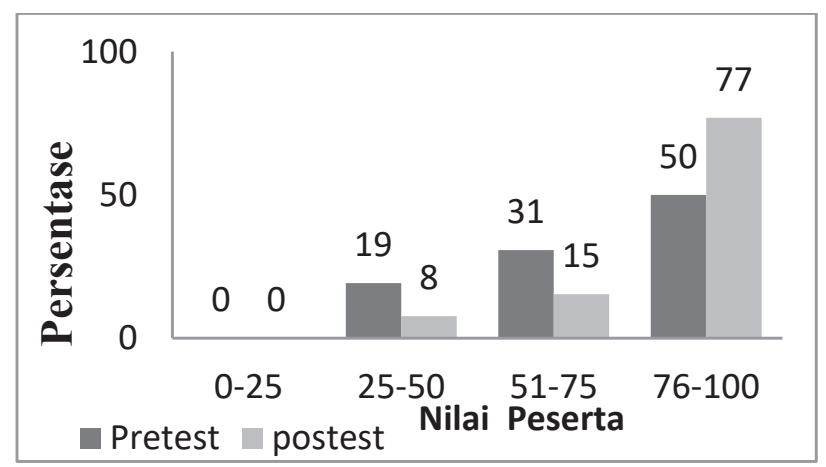

Gambar 2. Hasil pretest dan post test peserta pelatihan budidaya jamur tiram.

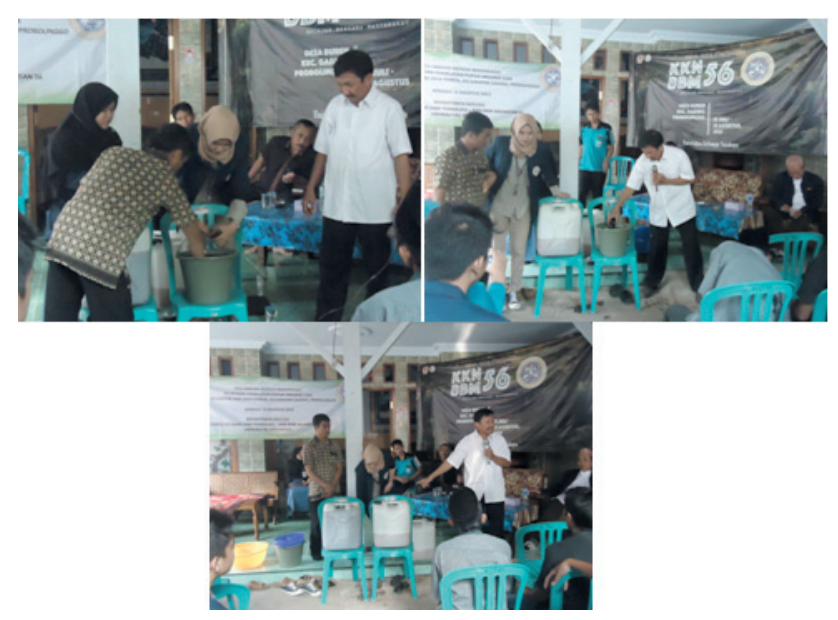

Gambar 3. Praktek pembuatan pupuk organik cair.

Kelompok tani selanjutnya melakukan praktek tentang pembuatan pupuk organik cair. Hasil evaluasi kegiatan pembuatan pupuk organik cair menunjukkan bahwa kelompok tani telah mampu membuat pupuk organik cair dengan baik (Gambar 3). Tujuan pelatihan ini adalah untuk meningkatkan pengetahuan petani tentang pembuatan pupuk organik cair.

\section{SIMPULAN, SARAN, DAN REKOMENDASI}

Simpulan dari program pengabdian masyarakat ini adalah proses sosialisasi mampu meningkatkan wawasan kelompok tani. 77\% kelompok tani paham dengan pembuatan pupuk organik cair. Pengabdian masyarakat ini juga menyediakan fasilitas pupuk organik cair, molase agar para kelompok tani menjadi mandiri untuk pembuatan pupuk organik. Pembuatan pupuk organik cair dapat memberikan tambahan nilai ekonomi bagi kelompok tani dari segi kualitas produk pascapanen yaitu berupa produk organik.

Sarannya agar program pendampingan masyarakat ini dapat dilanjutkan untuk pemasaran produk tani ke luar wilayah lokasi Pengabdian Masyarakat. Kelompok tani di lain tepat juga dapat direkomendasikan apabila memungkinkan untuk pelaksanaan program pengabdian masyarakat sejenis.

\section{UCAPAN TERIMA KASIH}

Kegiatan ini dibiayai oleh Bantuan Pendanaan Perguruan Tinggi Negeri (BPPTNBH) Universitas Airlangga sesuai dengan Surat Keputusan Rektor Universitas Airlangga Nomor : 1127/UN3/2017, tanggal 11 Agustus 2017. Terima kasih diucapkan kepada kelompok tani Desa Duren Kecamatan Gading Kabupaten Probolinggo atas kerja samanya dalam pelaksanaan kegiatan ini.

\section{DAFTAR PUSTAKA}

Alexander, M. 1978. Introduction to Soil Microbiology, $2^{\text {nd }}$ ed, Willey Eastern Limited, New Delhi.

Buntan, A. 1992. Efektivitas bakteri pelarut fosfat dalam kompos terhadap peningkatan serapan P dan efisiensi pemupukan $\mathrm{P}$ pada tanaman jagung, Tesis, Program Pascasarjana IPB, Bogor Goenadi, D. H., 2004, Teknologi Konsumsi Pupuk yang Minimal, Kompas, 15 Mei 2004.

Illmer, P., A. Barbato dan F. Schinner, 1995. Solubilizing of hardly soluble AlPO4 with P-solubilizing microorganism, Soil Biol, Biochem, 27, 265-270.

Musnamar, E. I. 2003. Pupuk Organik Padat: Pembuatan dan Aplikasinya, Jakarta: Penebar Swadaya.

Subba Rao, N.S. 1982. Biofertilizers in Agriculture, A.A. Blakema/Rotterdam, New Delhi

Subba Rao, N.S. 1993. Mikroorganisme Tanah dan Pertumbuhan Tanaman, Edisi Pertama, Terjemahan Herawati Susilo, UI Press.

Suriawiria, U. 2002. Pupuk Organik Kompos dari Sampah. Bandung Humaniora, 53. 